\title{
"Pai e construtor da arte brasileira" - A Academia das Belas Artes na reforma da educação promovida por Benjamin Constant em 1890/1891
}

\begin{abstract}
RESUMO: No decorrer da década de 1880, a Academia Imperial de Belas Artes foi alvo de avaliações desfavoráveis por parte de críticos de arte e de alguns de seus professores e alunos. Exigia-se uma reforma urgente da estrutura e dos métodos de ensino da instituição. Com o advento da República, em novembro de 1889, a ansiada reformulação começou a se tornar realidade através da nomeação de uma comissão incumbida de elaborar o projeto de reforma da Academia. Depois de muitos debates ao longo de 1890 sobre o modo como a Reforma deveria ser conduzida, o então ministro da Instrução Pública, Correios e Telégrafos, Benjamin Constant, aprovou os Estatutos da Escola Nacional das Belas Artes, em 8 de novembro daquele ano, com o decreto $\mathrm{n}$. 983 . O presente artigo apresenta a 'Reforma de 1890' como parte da reforma de educação de Benjamin Constant, colocada em prática nos anos de 1890 e 1891.
\end{abstract}

Palavras-chave: Reforma da Academia das Belas Artes - Reforma da Educação de Benjamin Constant - Ensino Artístico.

ABSTRACT: In the course of the 1880s the Imperial Academy of Fine Arts (Rio de Janeiro/Brazil) was the target of negative reviews on the part of art critics and some of its own teachers, students and directors: they demanded an urgent reform of the structure and teaching methods of the institution. With the advent of the Republic, in November of 1889, the desired reform began to become a reality through the appointment of a commission responsible to design a reform project for the Academy. After many debates during 1890 on how reform should be conducted, the Minister of Public Instruction, Posts and Telegraphs, Benjamin Constant, approved with Decree 983, the Statutes of the National School of Fine Arts, on November 8 of the same year. This paper presents the 'Reform of 1890' as part of the Educational Reform of Benjamin Constant, acted in the years 1890 and 1891.

Key-words: Reform of the Academy of Fine Arts - Educational Reform of Benjamin Constant - Artistic Education.

$*$

Pela Academia III

Bem orientado e criterioso, dispondo destes elementos todos, o Sr. Benjamin Constant está, por conseguinte, nas condições perfeitas de tornar-se o pai e construtor da Arte Brasileira (grifo nosso). (Mallet, 1891, p.1)

Em 1890, ano posterior ao da proclamação da República, ocorre a chamada 'Reforma da Academia', que transformou a antiga Academia de Belas Artes ${ }^{1}$, localizada no Rio de Janeiro, em Escola Nacional de Belas Artes.

No decorrer da década de 1880, a Academia de Belas Artes foi alvo de avaliações desfavoráveis por parte de críticos de arte e de alguns de seus professores e alunos.

\footnotetext{
${ }^{1}$ Devemos recordar que em 1889 a Academia havia perdido o Imperial do seu nome, graças a implementação da República.
} 
Exigia-se uma reforma urgente da estrutura e dos métodos de ensino da instituição. Com o advento da República, em novembro de 1889, a ansiada reformulação começou a se tornar realidade através da nomeação de uma comissão incumbida de elaborar o projeto de reforma da Academia. Depois de muitos debates ao longo de 1890, sobre o modo como a Reforma deveria ser conduzida, o então ministro da Instrução Pública, Correios e Telégrafos, Benjamin Constant, aprovou os Estatutos da Escola Nacional das Belas Artes, em 8 de novembro daquele ano, com o decreto n. 983. (DAZZI, 2011, p.2). Ainda em novembro daquele ano, o escultor Rodolpho Bernardelli foi nomeado o primeiro diretor da Escola. (BERNARDELLI, 1891, p.13). ${ }^{2}$ Os anos que se seguiram à sua nomeação foram os de implementação dos Estatutos de $1890^{3}$ e de concretização das melhorias que vinham desde há muito tempo sendo exigidas.

Procuraremos mostrar com o presente texto que o surgimento da Escola Nacional de Belas Artes estava conectado à uma reforma de proporções bem mais significativas, colocada em prática pelo então Ministro da Instrução publica Benjamin Constant. Nos anos iniciais da República (1889-1930) o "entusiasmo pela educação" e o "otimismo pedagógico" que caracterizaram o momento levaram intelectuais a atribuir à educação a solução dos graves problemas que então ameaçavam o desenvolvimento do Brasil. (OLIVEIRA, 2006, p. 110). É nesse contexto que ocorre a Reforma Benjamin Constant (1890/1891). Trata-se da primeira reforma educacional do período republicano, estando no ápice das mudanças conjunturais advindas da Proclamação da República. (SILVA, 2012, p. 14-16).

Benjamin Constant foi chefe do Ministério da Instrução Pública, Correios e Telégrafos, criado pelo governo provisório com o Decreto no. 346 de 19 de abril de 1890, ficando responsável pelos assuntos relativos à Instrução Pública, os Estabelecimentos de Ensino especiais ou profissionais, os Institutos, Academias e Sociedades dedicadas às ciências, letras e artes, além dos serviços dos Correios e Telégrafos. No decorrer dos dois anos que esteve a frente do Ministério, Benjamin empreendeu grandes mudanças na educação, e não só no que se refere a instrução militar ou ao Instituto Nacional de Cegos. Todos os campos da educação foram contemplados, inclusive a artística. (LLOPIS, 2008, p. 2-3).

As mudanças (e dentre elas muitas melhorias) incluíam do ensino primário ao ensino normal, do ensino técnico-profissional ao ensino superior, abrangendo as mais diversas modalidades do conhecimento (medicina, direito, música etc.). Benjamin Constant, igualmente, criou novas instituições de ensino, como o Pedagogium e a Escola de Astronomia e Engenharia Geográfica. Por certo, nesse contexto, o ensino das belas artes não poderia ser deixado de lado, sendo incorporado, por meio da aprovação dos Estatutos

\footnotetext{
2 O escultor foi nomeado por decreto de 14 de novembro de 1890 . Informação fornecida pelo próprio Rodolpho Bernardelli no seu relatório de 1891.

${ }^{3}$ Estatutos referentes ao decreto n. 938, de 8 de novembro de 1890. Instituição da Escola Nacional de Belas Artes e do Conselho Superior de Belas Artes
} 
da Escola Nacional de Belas Artes, assinados por Benjamin Constant em 8 de novembro de 1890. (DELANEZE, 2007, p. 16-18).

Como destaca Maria Teresa Cartolano em sua tese de doutorado:

Benjamin Constant (1836-1891) militar por formação e professor por vocação foi um homem do seu tempo e um cidadão comprometido com os problemas sociais e políticos da sociedade da época. Mesmo inspirado por algumas ideias do cientificismo comteano, não deixou de dar consideração ao indivíduo e à sua espontaneidade e/ou criatividade; dedicou grande parte da sua vida ao exercício do magistério e a pensar a educação brasileira como meio de reconstrução e redenção nacional. Nas reformas que empreendeu na instrução pública do Distrito Federal e que se tornaram modelares para o resto do país, enfatizou um novo método de ensino: a lição de coisas, ou através das coisas. (CARTOLANO, 2010, s/p)

Tendo como fonte primária documentos de época, é possível identificarmos uma série de relações entre os ideais que conduziram a Reforma da Academia e aqueles que guiaram a Reforma da Educação de Benjamin Constant.

Pensar o surgimento da Escola Nacional de Belas Artes como parte desse processo nos possibilita identificar e corrigir afirmações como a que segue abaixo:

Benjamin Constant foi a figura que encabeçou o movimento de positivistas brasileiros, o qual se formara em Bruxelas à época da República. Elaborou a primeira reforma educacional republicana denominada Reforma Benjamin Constant. Tal reforma propunha a extinção da Academia Imperial de Belas Artes e a disseminação do Ensino da arte como imitação, difundido em todas as escolas públicas de todos os graus. No entanto, defensores do liberalismo - o grupo dos irmãos Bernardelli - conseguiram garantir a sobrevivência da Academia, mudando a denominação para Escola Nacional de Belas Artes sem, no entanto, alterar seus moldes arcaicos (grifos nossos). (BARBOSA, 2002, p. 65-67 APUD FISCH, 2006, p. 24)

O parágrafo reúne alguns erros históricos. Benjamin Constant não desejava o fim da Academia Imperial de Belas Artes, pois, se o desejasse, o teria empreendido. Nem foi a Reforma da Academia somente uma mudança de denominação. Constant sabia que era importante uma renovação efetiva do sistema de ensino da Academia. Reconhecia o valor da arte e, muito mais, sabia que, para pôr em prática a sua Reforma da Educação, seriam necessários professores de desenho saídos da instituição.

Graças à Constituição de 1891, que promoveu a descentralização administrativa, a Reforma Benjamin Constant se centrou, em grande medida, no Rio de Janeiro. Assim, se por um lado, a Reforma Benjamin Constant expressava a descentralização, por outro funcionava como ponto de referência e modelo para outras iniciativas oficiais ou particulares no campo da instrução nacional. A Escola Nacional de Belas Artes, portanto, deveria ser uma escola de belas artes modelo. (MACHADO, 2008, p. 103-121). 
Passaremos agora a abordar dois tópicos que evidenciam que a Reforma da Academia estava conectada à reforma da educação de Benjamin Constant, e não somente por ter seus estatutos aprovados durante o período de Benjamin a frente do ministério da Instrução Pública. Trata-se do ensino pensado de forma seriada e a importância atribuida a intuição como método de ensino.

Ponto de grande destaque e inovação na Reforma Benjamin Constant foi a organicidade conferida às etapas do processo educativo. Até finais do século XIX no Brasil, vigorou o pressuposto de que as disciplinas eram independentes, assim, ao receber certificados de exames que podiam ser prestados em diferentes épocas, o estudante possuía o atestado de que conhecia o conteúdo do estudo e estava apto a seguir para o curso superior, independentemente da idade e dos anos que passara se dedicando aos estudos. Os conhecimentos eram avulsos, decorados e sem conexão entre si, não proporcionando uma educação eficaz. Com Benjamin Constant, o ensino foi pensado de acordo com uma seriação sistemática, partindo sempre daquilo que já era conhecido e observado pelos sentidos, do conhecimento mais geral e menos complicado para o desconhecido, para o abstrato, para o mais especializado e o mais complexo. (NUNES, 2003, p. 13).

Era preciso, portanto, considerar as disciplinas como sequências lógicas. Não deveriam ser oferecidos apenas conteúdos avulsos (sem sucessão), que não possuíssem relações entre si, pois a verdadeira instrução consistia, não em estudos desagregados, mas no desenvolvimento harmônico do entendimento, mediante a ação convergente de disciplinas apropriadas, aprendidas na sua gradação lógica e na sua colaboração natural.

Sabemos pela análise do Projeto Bernardelli-Amoêdo, que propunha a Reforma da Academia, e dos Estatutos que passaram a vigorar na Escola após 1890, que a seriação foi fundamental para a reestruturação do sistema de ensino da antiga Academia.

É significativo mencionar que na Academia, antes da reforma, não havia um "currículo" rigoroso (ao menos na prática), considerando-se um conjunto de estudos ordenados e hierarquizados, e poucas eram as disciplinas cujo desenvolvimento estava condicionado a uma duração prefixada. Essa foi uma das principais críticas em relação ao sistema de ensino da Academia, e a principal melhora apontada com a sua transformação em Escola. Segundo o relatório ministerial primeiro diretor da Escola Nacional de Belas Artes, o escultor Rodolpho Bernardelli, datado de 1891:

A Academia era pura e simplesmente um descalabro. [...] Praticamente, concretizando-se em ensino, a desordem era mais flagrante e a mais funesta. [...] Não se havendo classificado os trabalhos n'uma série evolutiva que fossem ao mesmo tempo a ordem e a facilidade, só o improviso dos diretores determinava aos alunos o seguimento do curso.

Sucedia que era preferido dentro da lei para primeira applicação de actividade dos alunnos o estudo do desenho figurado, como poderia dentro da mesma lei ser preferido o da pintura histórica.Não se havendo 
preestabelecido legalmente a duração dos estudos, vicio de omissão a respeito de tempo em harmonia com a omissão a respeito da ordem, os alumnos, sem o devido preparo, adiantavam [...]. A simples vigilancia dos exames e concursos não podia marcar a necessaria demora nos estudos. (BERNARDELLI, 1891, p.14-15)

O funcionamento da Academia lembrava, guardadas as devidas proporções, aquele das aulas régias, que parecem ter perdurado no Brasil Império. Cada aula régia constituía uma unidade de ensino, com um único professor, para determinada disciplina. Era autônoma e isolada, pois não se articulava com outras e nem pertencia a uma escola. O aluno se matriculava em tantas aulas quantas fossem as disciplinas que desejasse.

A nova seriação iniciada na Escola Nacional de Belas Artes com a implementação da Reforma de 1890 permitiu, segundo Rodolpho Bernardelli, atender a "todos os cuidados capazes de fazer [da] instituição uma escola preparatória de primeira ordem":

Na organização didatica dos novos estatutos reina, sobretudo, o primeiro dos elementos de que deriva a efficacia de qualquer ensino - a systematização.

Como conjunto theorico, ai está preparada a seriação dos conhecimentos, de maneira que o alunno progrida dos mais accessiveis para os mais difficeis na razão do desenvolvimento das faculdades, com o tempo e os exercicios (grifos nossos). (BERNARDELLI, 1891, p.14-15)

Vemos nessa passagem como Bernardelli estava em sintonia com aquela que foi uma das principais mudanças propostas por Benjamin Constant à educação. A Escola Nacional de Belas Artes, na qualidade de modelo para o resto do país, deveria seguir o preceito da seriação dos conhecimentos, ainda que repensado e adaptado à sua realidade.

O outro tópico que merece especial atenção é o que diz respeito ao ensino intuitivo ou ensino através dos sentidos, também conhecido como "lição das coisas". Sabemos que em fins do século XIX a "intuição" e a "sensação" estavam profundamente ligadas a ideia de modernidade, tendo ganhado importância no fazer artístico, sobretudo à quele voltado a pintura de paisagem. (SCHAPIRO, 2002. p. 38-40.)

Os dois princípios, "intuição" e "sensação", abrigavam a liberdade dos preceitos acadêmicos e a originalidade pessoal dos artistas. Também sabemos, pelos teóricos da educação, que a intuição/sensação não era pensada apenas pelo meio artístico, mas enfatizada como fundamental no processo educativo. ${ }^{4}$

Através do método de ensino intuitivo, buscava-se a educação a partir de novos padrões intelectuais, originados numa recente concepção sobre o conhecimento. Tendo surgido na Alemanha no final do século XVIII o método intuitivo consistia na valorização da intuição

\footnotetext{
${ }^{4}$ Referimo-nos aqui a trabalhos teóricos recentes, redigidos, sobretudo, por estudiosos de história da educação brasileira. Tais trabalhos podem ser localidos nas Referências do presente artigo, tendo sido as obras lá listadas utilizadas ao longo do texto.
} 
como fundamento de todo o conhecimento, isto é, a compreensão de que a aquisição dos conhecimentos decorria dos sentidos e da observação. (REMER, 2009, p. 6335-6337). O que de forma muito clara remete aos escritos sobre a arte do século XIX, que valorizavam os sentidos e a observação direta da natureza.

Bom exemplo é esse breve trecho de um texto dedicado a Exposição dos Artistas independentes, publicado em 1880 na Gazette des Beaux -Arts, por Charles Ephrussi, que sintetizava dessa modo a postura do artista moderno:

\begin{abstract}
Compor seu quadro não no ateliê, mas na natureza; em presença do assunto tratado se desembaraçar de toda convenção; se colocar face a face com a natureza e a interpretar sinceramente, brutalmente, sem se preocupar com a maneira oficial de ver; traduzir escrupulosamente a impressão, a sensação, cruamente, por mais estranha que ela possa parecer [...] Eis o ideal da nouvelle école. Ela não se submete mais ao catechismo óptico; ela faz o que vê, como vê, espontaneamente, bem ou mal... (EPHRUSSI, 1880, p. 485-488)
\end{abstract}

Voltando-se à educação, o método foi fundamentado especialmente nas ideias de Pestalozzi e Froebel, a sua superioridade consistia na disposição de fatos e objetos para observação dos alunos e, a partir dela, o conhecimento emergia, apresentando dados fornecidos pelo próprio objeto. Intuição, segundo os pensadores do método, era a capacidade de ver, de observar. (RESENDE, 2002, p. 12).

Por esse motivo, a educação dos sentidos e por meio deles substituia os exercícios de memorização por um contato direto com o elemento em estudo e com o mundo circundante.

Etimologicamente, a intuição ("in", em, e "tueri", contemplar) é o conhecimento direto, imediato da verdade. Pedagogicamente, a intuição era, então, esse contato com os objetos, os seres e os acontecimentos, seja por meio de atos motores (manuais e gestuais), seja por intermédio dos sentidos (contatos sensoriais) e, mais particularmente, da visão. (CARTOLANO, 2010, s/p).

O método intuitivo foi amplamente divulgado na Europa na segunda metade do século XIX, quando o movimento de renovação pedagógica entrou em sua fase ativa, tornandose um marco de renovação educacional. No Brasil, passou a ser a tendência norteadora do ensino graças à influência que esse pensamento educacional europeu exerceu sobre o intelectual e político Rui Barbosa e, posteriormente, sobre Benjamin Constant.

Os pensamentos de Rui Barbosa foram expostos em artigos de jornais, em programas de governo, em discursos na Câmara dos Deputados, em projetos de reforma e, principalmente, nos pareceres sobre a educação primária.

No parecer de Rui Barbosa sobre a reforma do ensino primário, o método intuitivo foi exaltado como o elemento mais importante de toda a reforma: "Cumpre renovar o método, orgânica, substancial, absolutamente, nas nossas escolas. Ou antes, cumpre criar o 
método...". (BARBOSA, 1946, p. 61-62) Somente esse método poderia triunfar sobre o ensino verbalista, repetitivo, enraizado na memória e nas abstrações inúteis praticado nas escolas do Império. Ele deveria se constituir em um princípio geral, abrangendo todo o programa e não um assunto específico, um item entre o rol de matérias.

Em relação à difusão do método intuitivo, Rui Barbosa se dedicou, também, à tradução do livro de Norman Allison Calkins, Primary Object Lessons, publicando-o no Brasil em 1886, com o título Primeiras Lições de Coisa.

Em função da Reforma Benjamin Constant adotar como método pedagógico o método intuitivo, os livros tiveram apenas uma função complementar no ensino, conforme o artigo 30, parágrafo 10, do Decreto n. 98138: "Em todos os cursos será constantemente empregado o methodo intuitivo, servindo o livro de simples auxiliar, e de accordo com programmas minuciosamente especificados". (BRASIL, 1890, p.3476) De acordo com Cartolano:

\footnotetext{
No que diz respeito ao método, a reforma privilegiava o intuitivo, além de incentivar a espontaneidade, a curiosidade do educando e a sua participação, ainda que incipiente.

Sempre auxiliado em todos os momentos pelas 'coleções de coisas' que professores e alunos ajudavam a formar e que se convencionou chamar 'museu escolar' conforme texto do Art. $9^{\circ}$ do Decreto citado.

Entendo, ainda, a esse respeito, que afora a referência à ordem natural, ao destaque dado à observação, além daquele dado à graduação dos estudos, [...] o Regulamento Constant, ao mesmo tempo, indicava e reforçava o ensino intuitivo e as lições de coisas (grifos nossos). (CARTOLANO, 1994, p. 169-171)
}

Assim, no que diz respeito ao método a reforma Benjamin Cosntant privilegiou o intuitivo, além de incentivar a espontaneidade, a curiosidade e dar destaque à observação direta das coisas. O que poderia estar mais próximo da concepção de arte moderna de finais do Oitocentos?

Rodolpho Bernardelli deve ter entrado em contato com os pressupostos do método intuitivo através dos pedagogos brasileiros e das propostas de Benjamin Constant e, igualmente, através de teóricos da arte como o francês Félix Ravaisson, defensor do uso do método intuitivo no ensino de desenho.

Para Ravaisson a "exatidão e a correção" não levariam à formação de melhores trabalhadores nas artes industriais, pois com o tempo elas atrofiavam a personalidade e impediam a formação da individualidade, assim como da sensibilidade e do gosto artístico. (PELLISSON, 1911, s/p).

Ao método intuitivo se contrapunha o ensino de desenho meramente geométrico, que vigorou nos currículos escolares franceses nas décadas de 1860 e 1870 . Nos anos de 1880, teve início uma reação geral na Europa a favor do método intuitivo. De um lado, criticavase os desenhistas formados pelo método oficial com a afirmação de que eram medíocres; 
de outro, os professores constatavam que os resultados de suas aulas não correspondiam ao que era desejado e aos esforços empregados. Era mister um novo método, que estimulasse nos alunos o hábito da observação direta. Também um método mais ativo, ou seja, que não visasse somente obter dos alunos uma reprodução exata de um modelo, mas que desenvolvesse neles o desejo e os meios de aplicar a uma ideia pessoal as noções que adquiriam. Essa necessidade fez com que o método intuitivo fosse adotado por instituições de ensino de modo geral. (PELLISSON, 1911, s/p).

A proposta do método intuitivo é perceptível no Relatório Ministerial que Rodolpho Bernardelli redigiu em 1891.

\begin{abstract}
A Academia crua contemplação ritual do passado; era a veneração do canon inviolavel das convenções plasticas dos antigos, distrahindo o espirito dos artistas do especulo ensinador da natureza, era a lição tyrannica do 'como viam', contrapondo-se ao ensino intuitivo e natural do 'como vêdes' [...]. A Escola, desobrigando-se de epitheto academico, nada mais deseja ser do que o livre ensino, conforme a natureza se revela e conforme os temperamentos a comprehendem... (grifos nossos). (BERNARDELLI, 1891, p. 13-14)
\end{abstract}

O trecho citado expõe de forma clara o pensamento de Rodolpho Bernardelli, não somente como artista-escultor, mas como artista-educador, o que de fato ele foi por décadas, após o seu regresso da Itália em 1885. (DAZZI, 2012, p. v. 1. p. 260). O ensino acadêmico de arte era a "lição tirânica do como viam", ele distanciava o aluno, o estudante do "espetáculo ensinador da natureza".

Podemos afirmar que a seriação do ensino assim como o método intuitivo de ensinar e aprender assumiram grande relevância na reforma da Academia, não somente pelo que representavam no âmbito artístico, mas por sua significação maior em relação às inovações educacionais dentro do contexto da Reforma Benjamin Constant.

Para além dos tópicos anteriormente analisados, os quais evidenciam que a reforma da Academia teve relações diretas com a Reforma Educacional de Benjamin Constant, devemos considerar mais um fator de grande importância para a compreensão das modificações implementadas na Escola Nacional de Belas Artes após 1890. Trata-se do fato de que parte dos artistas formados pela instituição atuaria como professores de desenho para crianças em escolas primárias de $2^{\circ} \mathrm{grau}$ ou, ainda, como mestres na formação de professores que, posteriormente, lecionariam nas escolas primárias de $1^{0} \mathrm{grau}$. Se recordarmos que, no Brasil de finais do século XIX, havia um mercado incipiente de arte em formação, para grande parcela dos artistas, atuar como professores de desenho se apresentava como uma opção bastante atrativa. E os salários não eram ruins. Com base no Decreto n. 981 , de 8 de novembro de 1890 , sabemos que o vencimento dos professores das escolas primárias de $2^{\circ}$ grau era de 4:000\$000 réis. Já um professor da Escola Nacional 
de Belas Artes, segundo os Estatutos de 1890, tinha o vencimento de cerca de 5:600\$000 réis.

A atuação de artistas vinculados à Escola Nacional de Belas Artes em instituições públicas e privadas de ensino nos anos finais do século XIX só foi possível graças ao Decreto n. 981, assinado por Benjamin Constant, que instituiu o ensino de desenho em todos níveis da educação (nas escolas primárias, no Ginásio e no ensino normal). E não se tratava do ensino de geometria, pois o ensino de desenho geométrico e o ensino de desenho eram pensados como disciplinas independentes. ${ }^{5}$

Rafael Frederico, pintor que estudou na década de 1890 na Escola Nacional de Belas Artes e foi vencedor do Prêmio de Viagem em 1893, é um bom exemplo de artista formado pela instituição que atuou como professor de desenho em diferentes níveis do ensino, lecionando em escolas públicas e privadas e na Escola Normal. ${ }^{6}$ (GALVÃO, 1965, p.65) Outros artistas saídos da Escola Nacional de Belas Artes lecionaram igualmente em escolas primárias ou demais instituições de ensino, mas, infelizmente, como esse tipo de atuação não é valorizado na história da arte brasileira do século XIX, por ser considerado irrelevante e mesmo negativo, seria necessária uma pesquisa específica para dar conta do levantamento desses dados.

A atuação de tais artistas como professores em escolas secundárias, normais e profissionalizantes, no entanto, é extremamente valiosa, não deve ser omitida ou vista como um mero detalhe negativo em uma trajetória artística, pois nos permite compreender melhor os direcionamentos que o sistema de formação artística tomou em finais do século XIX no Brasil.

O professorado do ensino de desenho nas escolas, graças à Reforma Benjamin Constant, se apresentava, em 1890, como um campo novo e vasto de atuação. Retomemos aqui as palavras de Rodolpho Bernardelli, em seu Relatório de 1891:

[...] seria de imennsa vantagem que os iniciadores da lei em nosso paiz reservassem exclusivamente para os portadores de diplomas da Escola Nacional o direito ao professorado publico das artes plásticas em qualquer grito de desenvolvimento (grifo nosso). (BERNARDELLI, 1891, p.20)

Concluímos dessa passagem que Rodolpho Bernardelli expressava uma vontade que não era só dele, mas de outros artistas que reconheciam no magistério uma possibilidade de trabalho e renda para os jovens artistas que saíam da Escola Nacional de Belas Artes. Bernardelli também deveria saber que, para atuarem como professores dentro da nova

\footnotetext{
${ }^{5} \mathrm{O}$ ensino primário, por exemplo, não contava com aulas de geometria, mas já dispunha de aulas de desenho, conforme o Decreto n. 981, de 8 de novembro de 1890.

${ }^{6}$ Segundo Alfredo Galvão, Rafael Frederico também atuou no Instituto Profissional Masculino e no Instituto Profissional Feminino, foi professor da Escola de Aperfeiçoamento Técnico para adolescentes e adultos, da Escola Amaro Cavalcante, do Colégio Ranipi Williams e do Colégio Mundo Novo.
} 
realidade concebida por Benjamin Constant, esses artistas necessitavam de um direcionamento especial em sua formação. Benjamin Constant igualmente tinha conhecimento disso.

Para explicarmos como se deu esse novo direcionamento, primeiramente, explanaremos sobre como o ensino de desenho foi concebido na Reforma Benjamin Constant.

O documento referencial para uma análise das mudanças pelas quais passou o ensino a partir da Reforma Benjamin Constant é o Decreto n. 981, de 8 de novembro de 1890, que aprovou o regulamento da Instrução Primária e Secundária do Distrito Federal. Vejamos como o ensino de desenho estava inserido nas escolas primárias de $1^{\circ}$ e $2^{\circ} \mathrm{grau}$, na escola normal e no ensino secundário oferecido no Ginásio Nacional.

Art. $3^{\circ} \mathrm{O}$ ensino das escolas primarias do $\mathbf{1}^{\circ}$ gráo, que abrange tres cursos, comprehende:

Leitura e escripta; Ensino pratico da lingua portugueza; Contar e calcular [...] Elementos de geographia e historia, especialmente do Brazil; [...] Instrucção moral e civica; Desenho; Elementos de musica; Gymnastica e exercicios militares; Trabalhos manuaes (para os meninos); Trabalhos de agulha (para as meninas); Noções praticas de agronomia.

Art. $40 \mathrm{O}$ ensino das escolas primarias do $2^{\circ}$ gráo, que abrange tres classes, comprehende: Calligraphia; Portuguez; [...] Arithmetica (estudo complementar). Algebra elementar. Geometria e trigonometria; Geographia e historia, particularmente do Brazil; Elementos de sciencias physicas e historia natural applicaveis ás indústrias, á agricultura e á hygiene; Noções de direito patrio e de economia politica; Desenho de ornato, de paisagem, figurado e topographico; Musica [...]. Art. 12. [...] O curso da Escola Normal comprehenderá as seguintes disciplinas: Portuguez, noções de litteratura nacional e elementos de lingua latina; Francez; Geographia e historia, particularmente do Brazil; Matematica elementar; Mechanica e astronomia; Physica e chimica; Biologia; Sociologia e moral; Noções de agronomia; Desenho; Musica; Gymnastica; Calligraphia; Trabalhos manuaes (para homens); Trabalhos de agulha (para senhoras).

Art. 26. O curso integral de estudos do Gymnasio Nacional será de sete annos, constando das seguintes disciplinas: Portuguez; Latim; Grego; Francez; Inglez; Allemão; Mathematica; Astronomia; Physica; Chimica; Historia natural; Biologia; Sociologia e moral; Geographia; Historia universal; Historia do Brazil; Litteratura nacional; Desenho; Gymnastica, evoluções militares e esgrima; Musica (grifos nossos). (BRASIL, 1890, p.3476)

A introdução do ensino de desenho em todas as séries que compunham os currículos dos ensinos primário e secundário e do curso normal, para além de outras explicações, fazia parte da própria filosofia positivista. Segundo o livro Principes D'education Positive:

A criança, tendo aprendido antes o que é útil, aprende dessa forma a compreender o que é belo, e ainda mais que o desenho deve ser ensinado junto com a escrita. [...]. O ensino primário deve iniciar com as noções de leitura, de escrita, de desenho, de música e do uso das línguas estrangeiras. [...]

A instrução secundária não deve interromper de forma alguma os estudos anteriores de música e de desenho, nem as aquisições empíricas e concretas sobre o nome e a procedência geral dos fenômenos e dos objetos 
meteorológicos, mineralógicos, botânicos e zoológicos. Ela deveria continuá-los e desenvolvê-los conforme as aptidões individuais, como coroamento, para aqueles que representando a maioria, são, desde que tenham força suficiente, levados por suas condições a se dedicar às artes agrícolas, industriais e comerciais. ${ }^{7}$ (BOURDET, 1877, p.8)

Era necessário suprir as escolas com professores de desenho; professores esses que soubessem passar para os alunos aquilo que se desejava.

O Decreto n. 981 expressava o que deveria ser ensinado nas escolas primárias:

\section{ESCOLA PRIMARIA DO $1^{\circ}$ GRÁO \\ Curso elementar \\ CLASSE $1^{a}$}

Linhas rectas e suas combinações representadas na lousa, e depois no papel a lapis preto e de côres. Reproducção de objectos usuaes

CLASSE $2^{a}$

Desenho - Traçado de linhas rectas e sua divisão em partes iguaes.

\section{Curso médio}

CLASSE $1^{a}$

Desenho - Principios de desenho de ornato. Circumferencias; polygonos regulares, rosaceas estrelladas. Curvas geometricas usuaes; curvas tiradas do reino vegetal. Caules, folhas, flores.

\section{CLASSE 2a}

Desenho - Continuação do estudo das curvas regulares; curvas ellipticas, espiraes, volutas

\section{Curso superior}

\section{CLASSE $1^{a}$}

Desenho - Elementos de perspectiva. Desenho de ornato em baixo relevo, cujos elementos procedem de fórmas vivas: folhas, flores ornamentaes, etc.

CLASSE $2^{a}$

Desenho - Continuação do desenho de ornato. Desenho de figura. Desenho de machinas simples. Exercicios de desenho topographico.

\section{ESCOLA PRIMARIA DO $2^{\circ}$ GRÁO}

\section{CLASSE $1^{a}$}

Desenho - Continuação dos exercicios da escola do $1^{\circ}$ gráo.

Desenho de ornato puramente geometrico. Folhas, flores e fructos: 3 horas.

CLASSE $2^{a}$

Desenho - Desenho do natural. Ordens architectonicas. Aguadas. 2 horas

CLASSE $3 a$

Desenho - Desenho de paisagem. Desenho de machinas simples.

Desenho topographico: 2 horas (grifos nossos). (BRASIL, 1890a, p.3476)

Sabemos que somente os alunos saídos do ensino normal poderiam ministrar aulas nos dois segmentos do ensino primário, mas, certamente, seriam necessários professores com formação artística para lecionar as aulas no próprio curso normal. Partindo-se do princípio

\footnotetext{
7 No original : «L'enfant, ayant appris d'abord ce qui est utile, apprend de la sorte à comprendre ce qui est beau, et d'autant mieux que le dessin doit être enseigné en même temps que l'écriture. [...] L'enseignement primaire doit débuter par les notions de lecture, d'écriture, de dessin, de musique et du parler des langues
} 
de que o professor que se formava no ensino normal ministrava essas aulas, ele deveria dominar esses conteúdos. Havia mesmo um segmento específico de arte na escola normal.

étrangères. [...] L'instruction secondaire ne doit interrompre aucunement les études antérieures de la musique et du dessin, non plus que les acquisitions empiriques et concrètes sur le nom et la provenance générale des phénomènes et des objets météorologiques, minéralogiques, botaniques et zoologiques. Elle devrait les continuer et les développer suivant les aptitudes individuelles, comme couronnement, pour ceux qui, représentant le plus grand nombre, sont, dès que les forces deviennent suffisantes, amenés par leur condition à se consacrer aux arts agricoles, industriels et commerciaux ».

O Decreto n. 982, de 8 de novembro de 1890, que deu novo regulamento à Escola Normal da Capital Federal, dividiu esse nível de ensino em Curso de ciências e letras e Curso de artes:

\section{Curso de artes}

Desenho: estudo geral do traço a mão livre (stigmographia). Desenho geometrico, inclusive o das ordens architetonicas e o de machinas simples. Desenho topografhico. Desenho do ornato, de paisagem e de figura.

$[\ldots]$

Art 25. O pessoal da escola [normal] constará de:

Um director; Dezesete proffessores, sendo: um de portuguez e latim, um de francês, um de geographia e historia, um de mathematica elementar, um de mecanica e astronomia, um de phisica e chímica, um de biologia, um de sociologia e moral, um de noções de agronomia, um de aula de applicação, dous de desenho [...] (grifo nosso). (BRASIL, 1890b, p.3476)

Sendo assim, durante os anos de formação no Instituto Normal, optando pelo curso de artes, o aluno recebia boa base de ensino de desenho, que incluía uma variação de habilidades: desenho linear, desenho de ornatos, desenho de paisagem, desenho topográfico, ordens arquitetônicas e desenho geométrico.

Tendo como referência o currículo do ensino primário, que deveria ser ministrado pelo professor normal, nos chama a atenção o destaque que era dado aos elementos da natureza, seja através do desenho de paisagem, seja através da estilização dos elementos naturais com o uso do desenho geométrico. Somente um professor com formação em belas artes poderia dominar esse currículo e passá-lo aos futuros educadores. De fato, sabemos que Rafael Frederico foi professor da Escola Normal. Já o ensino secundário, oferecido pelo Ginásio Nacional, foi tratado da seguinte maneira no Decreto 981/1890:

Art. 25. O ensino secundário integral será dado pelo Estado no Ginásio Nacional [...]. Art. 26. O curso integral de estudos do Ginásio Nacional será de sete anos, constando das seguintes disciplinas: Português; Latim; Grego; Francês; Inglês; Alemão; Matemática; Astronomia; Física; Química; História natural; Biologia; Sociologia e moral; Geografia; História universal; História do Brasil; Literatura nacional; Desenho; Ginástica, evoluções militares e esgrima; Música. [...] Art. 29. As disciplinas, a que se refere o art. 26, são todas obrigatórias, exceto: uma das duas línguas inglesa ou alemã, que o aluno escolherá à vontade para cursar e fazer exame (grifos nossos). (BRASIL, 1890a, p.3476) 
Através do decreto, sabemos que se ao ensino de desenho não era dada a mesma importância atribuída a matérias como a matemática, ele aparecia como disciplina obrigatória ao longo dos sete anos que compunham o ensino médio, devendo ter ministradas aulas semanais de 2 horas.

Tomemos como exemplo a estrutura do primeiro dos sete anos que compunham o ginásio, a qual se mantinha nos seis anos posteriores.

$1^{\text {a }}$ cadeira - Aritmética (estudo completo). Álgebra elementar (estudo completo): 6 horas por semana.

$2^{\mathrm{a}}$ cadeira - Português. Estudo completo da gramática expositiva. Exercícios de redação (com auxílio ministrado pelo lente): 3 horas.

[...]

Desenho, ginástica e música: $\mathbf{2}$ horas para cada matéria (grifos nossos). (BRASIL, 1890a, p.3476)

Um ponto que merece destaque é que o ensino primário poderia ter como meta formar, ao menos em parte, o "trabalhador brasileiro". O ensino ministrado no Ginásio Nacional era direcionado na época a uma minoria, pois eram muitos poucos aqueles que chegavam a receber um diploma do ensino secundário.

Art. 10 O Ginásio Nacional tem por fim proporcionar à mocidade brasileira a instrução secundária e fundamental, necessária e suficiente assim para a matrícula nos cursos superiores da República, como em geral para o bom desempenho dos deveres do cidadão na vida social (grifos nossos). (BRASIL, 1890a, p.3476)

Assim, a instrução de desenho no ensino médio não tinha como propósito formar artífices. O "bom desempenho dos deveres do cidadão na vida social" foi enfatizado pelo artigo 33 do Decreto 981/1890, que tratava do exame de madureza do ensino no Ginásio Nacional, "destinado a verificar se o aluno [tinha] a "cultura intelectual necessária", e pelo qual ele deveria passar para obter o diploma. O desenho, portanto, ensinado ao longo de sete anos, fazia parte dessa "cultura intelectual necessária".

Nesse sentido, o que um professor de desenho deveria saber lecionar para atuar do Ginásio Nacional? Seriam disciplinas diferentes daquelas ministradas no ensino primário?

Vejamos o programa de 1891 das aulas de desenho do Ginásio Nacional.

$1^{\circ}$ ano

Desenho Linear - Seus elementos, sua divisão em linear geométrico e linear a vista, sua utilidade e importância.

Desenho Linear Geométrico - Definições das principais figuras geométricas, suas propriedades e soluções dos problemas por processos gráficos; perspectiva linear e das sombras projetadas. Noções das ordens de Arquitetura.

$2^{\circ}$ ano

Desenho Linear a Vista - Exercícios gráficos das principais figuras geométricas sem auxílio de instrumentos de precisão; explicação dos seis tons de claro-escuro, exercícios de claro-escuro, da esfera, cilindro e prisma. 
30 ano

Desenho Imitativo-Representação de corpos de formas simples; ornatos arquitetônicos e industriais a lápis ou a esfuminho.

40 ano

Desenho de Paisagem - Flores e frutos a lápis ou a esfuminho.

50 ano

Desenho de Figura-Cabeças humanas e de animais a lápis ou a esfuminho.

(TRINCHÃO, 2008, p. 198)

Não parece serem essas noções muito diferentes das noções básicas de desenho que deveriam ser ministradas no ensino primário. Se vemos no ensino primário a referência às formas geométricas básicas, do desenho de ornatos, também as vemos no currículo do ginásio. Se no currículo do ensino secundário, é citado o desenho de paisagem e de figura, ele também é mencionado no ensino primário.

A base do conhecimento de um futuro trabalhador não parece, à primeira vista, ser tão diversa daquela de um futuro funcionário público ou de um futuro doutor. O fato é que os conhecimentos que os professores de desenho deveriam ter eram os mesmos e, certamente, para ministrá-los a todos os alunos era necessária a formação de um artista. Não por acaso, sabemos, com base nas memórias da filha de Rafael Frederico e nas memórias de Alfredo Galvão, que Rafael Frederico foi incumbido por Ramirez Galvão, Inspetor Geral da Instrução Pública, de organizar os programas de ensino de desenho das escolas de ensino médio, por volta de 1897. (GALVÃO, 1951, s/p)

Podemos afirmar que existia a preocupação, em 1890, com a formação de artistas capazes de atuar como professores nas escolas da República. Temos conhecimento de que os Estatutos da Escola Nacional de Belas Artes foram elaborados no final do ano de 1890 e, portanto, simultaneamente aos demais Decretos e Regulamentos da Reforma Benjamin Constant, que renovaram os ensinos primário, secundário e superior da Capital Federal e, consequentemente, de todo o país. Compreendemos, igualmente, que, para efetivar o seu "projeto" de reforma dos ensinos primário e secundário, Benjamin Constant precisava de professores de desenho que dessem conta do currículo por ele proposto. Nesse sentido, cremos que alguns itens dos Estatutos de 1890 da Escola Nacional de Belas Artes foram criados com o intento de formar artistas que, além de terem o preparo necessário para serem pintores e escultores, pudessem igualmente atuar, se o desejassem, como professores nessas escolas. Sabemos mesmo que essa era uma reivindicação do diretor da Instituição, Rodolpho Bernardelli, em 1891

(BERNARDELLI, 1891, p.20). ${ }^{8}$

\footnotetext{
${ }^{8}$ Para além da já citada passagem do Relatório de 1891, podemos aqui mencionar uma petição enviada ao Ministro do Interior, Aristides Lobo, ainda em dezembro de 1889. Os requerentes, entre eles Rodolpho Bernardelli, reunidos em três sessões, redigiram um documento que solicitava, dentre outros pontos, a obrigatoriedade do ensino de desenho em todos os níveis escolares e a proteção profissional aos habilitados a darem aulas de desenho. A petição foi publicada no Diário do Commercio, em 5 dez.1889, 9 dez.1889 e 21 dez. 1889, Floccos e no Correio do Povo em 9 dez. 1889.
} 
Uma das disciplinas que acreditamos ter sido incluída nos Estatutos de 1890 com esse propósito foi a de desenho linear, que não constava do currículo da antiga Academia, surgindo apenas em 1890. A disciplina também não aparecia no Projeto de Reforma de Bernardelli e Amoêdo, mas somente nos Estatutos de 1890 da Escola Nacional de Belas Artes, assinados por Benjamin Constant.

Neste sentido retomamos o pensamento de Rui Barbosa que - se não decisivo, pois cremos que Constant possuía suas próprias teorias sobre a educação -, foi de grande valor para a Reforma implementada pelo ministro da Instrução Pública, ao menos no que concerne ao ensino de desenho. Sabemos por teses e dissertações sobre Rui Barbosa que ele era um defensor do desenho linear ${ }^{9}$, método de ensino de desenho que teve grande sucesso na França da segunda metade do século XIX, quando foi implementada a disciplina nas escolas primárias daquele país. (REMER, 2009, p.6335-6337)

Basta uma leitura do programa do curso de desenho linear da Escola Nacional de Belas Artes para vermos que ele atendia a algumas das exigências impostas nos currículos das escolas primárias, do Ginásio Nacional e do Instituto Normal, anteriormente analisados:

Programa da Cadeira de Desenho Linear

10 Ano do Curso Geral

Elementos. Reprodução das diversas figuras geométricas, linhas, angulos, triangulos, poligonos, círculos, etc. tanto à mão 'levantada' como com auxílio de diversos instrumentos. Aplicações simples dos elementos à composição de ornatos, mosaicos, fregas, etc. [ilegível] à elementos architetonicos; [ilegível], janellas, etc.

Exercícios práticos; fazer a mão levantada [ilegível], de modelos diversos de elementos architetocnicos para depois com as [ilegível] medidas sobre o modelo reproduzido em proporção ortogonal.

Para complemento do curso, reprodução das ordens gregas e romanas, de ornamentos de diversos estágios clássicos, [ilegível]. Ass. Henrique Bahiana. ${ }^{10}$

Henrique Oscar Bahiana, professor que assinou, em 1891, o programa de desenho linear, nasceu em 1867, na Bahia, e estudou na França com recursos próprios. Na École de Beaux Arts teve êxito significativo no curso de arquitetura, chegando a ser admitido na $2^{\mathrm{a}}$ classe, como aluno de Jules André. Cursou concomitantemente a École Spéciale d'Architecture, diplomando-se em 1887. (PEREIRA, 2002, p.119-128). Em 1891, foi nomeado professor da Escola Nacional de Belas Artes.

Apesar da formação de Bahiana, a disciplina de desenho linear não fazia parte do curso específico dos arquitetos que cursavam a instituição, mas integrava as cadeiras

\footnotetext{
${ }^{9}$ É importante ressaltar que a Reforma Leôncio de Carvalho propunha somente "elementos de desenho linear na escola primária" (Art. $4^{\circ}$ ) e que a disciplina de desenho não se encontrava na preparação do professorado no currículo da escola normal, proposto para os estados (parágrafo primeiro do Art. 90). Aí está uma das características dos Pareceres de Rui Barbosa: propor uma reforma educacional em âmbito nacional, mudando o funcionamento da escola, a formação dos mestres e as finalidades da educação. ${ }^{10}$ Arquivo do Museu Dom João VI/EBA/UFRJ. Ata de 8 jun. 1891. p. 4A.
} 
obrigatórias do $1^{0}$ ano do curso geral, pelo qual todos os alunos da Escola Nacional de Belas Artes deveriam passar. Não necessariamente seria ministrada por um pintor ou escultor e, possivelmente, o mais indicado era de fato que fosse lecionada por um mestre com formação de arquiteto.

Vemos que a disciplina se ajustava perfeitamente a vários dos saberes que apareciam nos currículos escolares, faltando somente elementos como desenho de paisagem e de figura. Mas se a paisagem e a figura não integravam o programa de desenho linear proposto por Bahiana, os alunos da Escola Nacional de Belas Artes a ela tinham acesso em outras disciplinas, como desenho figurado.

Com efeito, o que era o desenho linear?

Foi o matemático Louis-Benjamin Francoeur o autor da primeira versão organizada dos fundamentos básicos do desenho. O manual Le Dessin Linéaire d'aprés Ia méthode de Enseignement mutuel, que passou nas edições seguintes a se chamar, simplesmente, Dessin Linéaire, apresentou a primeira organização de parte do conhecimento de desenho em forma de manual escolar, com o propósito de facilitar a inserção desse conhecimento no âmbito das escolas públicas e ajudar na capacitação de alunos e mestres. (TRINCHÃO, 2008, p. 88-110)

A obra tem grande significado para a história da disciplina e para a didática do desenho na esfera pública francesa e internacional, principalmente no Brasil e em Portugal. A primeira versão do manual data de 1819, tendo sido reeditado várias vezes. O exemplar de 1839 é o mais completo, pois, além das mudanças realizadas a partir das experiências de Francoeur, o conteúdo foi estendido, quase duplicado, e a redação foi direcionada, exclusivamente, para o ensino, com o objetivo de atender, especificamente, a educação primária.

"A instrução primária é a fonte principal donde decorrem as riquezas que se esperam da indústria", afirmou Francoeur, (Francoeur,1839, p.1) e as escolas, por sua vez, são o local de capacitação dos alunos mestres e de socialização dos saberes aos alunos das escolas primárias.

O Manual de Desenho Linear não era apenas uma seleção de conteúdo, mas um "método" de ensino elementar de desenho, isto é, um conjunto de procedimentos didáticos que fornecia noções para subsidiar o ensino de desenho em espaço escolar. Com esse conteúdo socializado através do manual, percebemos a complexidade do saber ensinado aos alunos das escolas francesas e, posteriormente, das escolas brasileiras.

Em sua tese de doutorado intitulada O Desenho como Objeto de Ensino, Glaucia Maria Costa Trinchão apresenta um quadro com um resumo da obra e do método didático de Francoeur, segundo a edição de 1839 do Manual de Desenho Linear. Segundo a tabela, o ensino de desenho de Francoeur englobava termos que vimos repetidas vezes nos currículos dos ensinos primário, secundário e normal após a Reforma Benjamin Constant: 
plantas com a régua e o compasso; da agrimensura; traçado de projeções e seu uso; imitação das formas irregulares, semelhantes às da natureza; da figura humana; da paisagem; das máquinas; da arquitetura e regras de perspectiva; imitação de figuras a mão livre. (TRINCHÃO, 2008, p. 272)

Surge a questão: como o nome de um método de ensino de desenho destinado ao primário se tornou uma das cadeiras do curso geral de Escola Nacional de Belas Artes?

Podemos justificar a sua inserção por duas vias. De um lado, conclui-se que o método de Francoeur era tido como tão eficiente que, no processo de realização dos estatutos, se pensou que seria interessante a sua inclusão no $1^{\circ}$ ano do curso geral, frequentado por jovens que não possuíam ainda uma base de conhecimento sobre o desenho. De outro, lembra-se que o termo desenho linear não aparece na proposta de Bernardelli-Amoêdo, nem nos comentários de nenhum articulista do período, o que nos leva a pensar que a sua inserção no currículo da Escola Nacional de Belas Artes se deu por iniciativa de um educador, no caso, Benjamin Constant. A sua presença no currículo da instituição só evidencia que a reforma do ensino de arte ministrado pela Academia fez parte de uma reforma maior do ensino no Brasil dos anos 1890 e 1891.

Acreditamos que foi possível comprovar, ao longo do presente texto, que surgimento da Escola Nacional de Belas Artes estava conectado à reforma da educação colocada em prática nos anos de 1890 e 1891 pelo então ministro da Instrução Pública, Correios e Telégrafos, Benjamin Constant. Evidenciamos que a Reforma da Academia foi inserida na discussão geral acerca da remodelação do ensino na República, ampliando, desse modo, o campo de debate acerca da Reforma de 1890. Procuramos instaurar um entendimento mais vasto do ensino ministrado na Escola, assinalando as relações desse ensino com o desenho, bem como lançando luz às mudanças reais e concretas que ocorreram quando da Reforma de 1890: a nova organicidade conferida às etapas do processo educativo e o uso do método intuitivo. Elucidamos, ainda, saber Benjamin Constant da importância da renovação efetiva do sistema de ensino da Academia. O ministro reconhecia o valor da arte e, muito mais, compreendia que, para pôr em prática a sua Reforma da educação, seriam necessários professores de desenho saídos da Escola Nacional de Belas Artes. Percepção que mostramos ser compartilhada pelo Diretor da instituição, Rodolpho Bernardelli, para quem a Escola deveria formar não somente pintores e escultores, mas preparar os artistas para atuação como professores de desenho nas escolas.

\section{REFERÊNCIAS DO TEXTO}

BARBOSA, Ana Mae. Arte e educação no Brasil. São Paulo: Perspectiva, 2002.

BARBOSA, Rui. Reforma do ensino primário e várias instituições complementares da instrução pública (1883). v. 10. Rio de Janeiro: Ministério da Educação e Saúde, 1947. 
BERNARDELLI, Rodolpho. Anexo H. Relatório Apresentado ao Presidente da República dos Estados Unidos do Brasil pelo Dr. João Barbalho Uchôa Cavalcanti, Ministro da Instrução Pública, Correios e Telégrafos, maio 1891. Disponível em: http://www.crl.edu/brazil>.

BOURDET, Eugène. Préface. Principes d'éducation positive. Paris: Librairie Germer Raillière, 1877.

BRASIL. Decreto n. 981 , de 8 de novembro de 1890 . Aprova o regulamento da instrução primária e secundária do Distrito Federal. Decretos do governo provisório da República dos Estados Unidos do Brazil. fascículo 11 ( $1^{\circ}$ a 30 de novembro de 1890). Rio de Janeiro: Imprensa Nacional, 1891. Disponível em: <http//: www2.camara.gov.br> .

BRASIL. Decreto n. 982, de 8 de novembro de 1890. Dá novo regulamento à Escola Normal da Capital Federal. Decretos do governo provisório da República dos Estados Unidos do Brazil. fascículo 11 ( $1^{\circ}$ a 30 de novembro de 1890). Rio de Janeiro: Imprensa Nacional, 1891. Disponível em: <http//: www2.camara.gov.br> .

CALKINS, Norman Allison. Primeiras Lições de Coisas. Tradução de Rui Barbosa. Rio de Janeiro: Imprensa Nacional, 1886.

CARTOLANO, Maria Teresa Penteado. Benjamin Constant: reconstrução nacional pela educação. Revista HISTEDBR, Campinas, n. 40, dez. 2010. Disponível em: $<$ http://www.histedbr.fae.unicamp.br/remate.html>

DELANEZE, Taís. As reformas educacionais de Benjamin Constant (1890-1891) e Francisco Campos (1930-1932): o projeto educacional das elites republicanas. São Carlos, 2007. Dissertação (Mestrado em Educação) - PPGE da Universidade Federal de São Carlos.

DAZZI, Camila. "Por em prática e Reforma da antiga Academia": a concepção e a implementação da reforma que instituiu a Escola Nacional de Belas Artes em 1890. Rio de Janeiro, 2011. Tese (Doutorado em História da Arte) - PPGAV/UFRJ.

DAZZI, Camila ; VALLE, Arthur. Os Professores da Escola Nacional de Belas Artes do Rio de Janeiro e a Arte Italiana Oitocentista. VI Jornadas de Historia del Arte 'VÍNCULOS

ARTÍSTICOS ITALIA-AMÉRICA, SILENCIO HISTORIOGRÁFICO (SIGLOS XVI AL XX).

Santiago: Museu Histórico Nacional do Chile, 2012.

EPHRUSSI, Charles. Exposition des Artistes Indépendants. Gazette des Beaux -Arts, 1et mai 1880.

FISCH, Carolina Betioli Ribeiro. A formação do arte-educador frente à epistemologia do ensino da arte: relações, contradições e perspectivas. Campinas, 2006. Dissertação de Mestrado. Pós-graduação em educação. PUC-Campinas.

FRANCOEUR, Louis-Benjamin. Dessin Linéaire et arpentage, pour touts les écoles primaires. Paris: Chez Louis Colar et Chez Bachelier, 1839.

GALVÃO, Alfredo. Introdução. Catálogo da exposição de Rafael Frederico. Rio de Janeiro: MNBA, 1951.

GALVÃO, Alfredo. Centenário de nascimento do pintor e professor Rafael Frederico. Arquivos da Escola Nacional de Belas Artes. Rio de Janeiro: EBA/UFRJ, 1965.

LLOPIS, Rosana. O Gymnasio Nacional sob a Reforma Benjamin Constant. V SIMPÓsIO NACIONAL ESTADO E PODER: HEGEMONIA, 2008, São Gonçalo e Niterói. Anais..., p. 23. Disponível em: <http://www.simposiohegemonia.pro.br>.

MACHADO, Maria Cristina Gomes. Carneiro Leão e a questão da educação superior. Revista Brasileira de História da Educação. São Paulo, n. 17, mai./ago. 2008.

MALLET, Pardal. Pela Academia III. Gazeta de Notícias, Rio de Janeiro, 26 jun. 1890.

NUNES, Antonieta de Aguiar. Política educacional no início da república na Bahia: duas versões do projeto liberal. Salvador, 2003. Tese (Doutorado em Educação) - Faculdade de Educação da Universidade Federal da Bahia.

OLIVEIRA, Dilma Maria Andrade de. Reformas de ensino e a construção da escola pública republicana - 1889/1930: o caso de Sergipe. LOMBARDI, J. C.; SAVIANI, D.; NASCIMENTO, M. I. M. (org.). Navegando pela História da Educação Brasileira. Campinas: FE/HISTEDBR, 2006. 
PELLISSON, Maurice. Dessin. In: Nouveau dictionnaire de pédagogie de Ferdinand Buisson.Paris: Hachette, 1911. Disponível em: <http://www.inrp.fr/inrp>.

PEREIRA, Sonia Gomes. A trajetória dos arquitetos e engenheiros brasileiros na Escola de Belas Artes de Paris no século XIX. XXI REUNIÃO DA SOCIEDADE BRASILEIRA DE PESQUISA HISTÓRICA. Curitiba, 2002. Anais... Curitiba: SBPH, 2002.

REMER, Maísa Milènne Zarur; STENTZLER, Márcia Marlene. Método intuitivo: Rui Barbosa e a preparação para a vida completa por meio da educação integral. Anais do IX Congresso Nacional de Educação. PUCPR, 2009. Disponível em: <http://www.pucpr.br> RESENDE, Fernanda Mendes. O domínio das coisas: o método intuitivo nas primeiras décadas republicanas. Belo Horizonte: UFMG, 2002. (Dissertação de Mestrado).

SCHAPIRO, Meyer. O conceito de Impressionismo. Impressionismo. São Paulo: Cosac Naify, 2002.

SILVA, Daniele Hungaro da. Inovações Educacionais nos anos de 1870 A 1890: Coeducação dos sexos e Método Intuitivo. Maringá: UEM, 2012. (Trabalho de Conclusão de Curso).

VALLE, Arthur Gomes. A pintura da Escola Nacional de Belas Artes na $1^{a}$ República (18901930): da formação do pintor aos "modos" estilísticos. Rio de Janeiro, 2007. Tese (Doutorado em História da Arte) - EBA/UFRJ.

Camila Dazzi (CEFET/RJ)

Recebido em: 17/09/2012

Aprovado em: 16/01/2013 